\title{
Is the El Niño-Southern Oscillation changing? Lessons from the past
}

\author{
Mary Elliot' ${ }^{1}$ S.Y. Cahyarini ${ }^{2}$, N. Abram ${ }^{3,4}$, T. Felis ${ }^{5}$ and H. McGregor ${ }^{6}$ \\ Belitung, Indonesia, 25-30 August 2019
}

A group of 50 scientists met in Belitung, Indonesia, in August 2019 to discuss past changes in the El Niño-Southern Oscillation (ENSO). ENSO is the main source of interannual climate variability that affects seasonal temperature and precipitation patterns across the Pacific Ocean with global teleconnections and severe societal and economic impacts. Research presented during this PAGES-supported meeting (pastglobalchanges.org/calendar/2019/127pages/1805) aimed to provide critical information required to better understand shortand long-term changes in ENSO. Recent findings were reviewed and our present understanding of the factors controlling past ENSO variance were assessed. Areas lacking information were identified, and a common and integrated strategy for future interdisciplinary studies was proposed.

Paleoclimate data, recently reviewed by Emile-Geay et al. (2020), provide unique information on the full range of natural variability of ENSO and enable assessments of rainfall and temperature anomalies and their impacts on marine and terrestrial ecosystems. Anomalies of sea surface temperature and salinity associated with past ENSO variability are primarily derived from seasonally resolved marine fossils such as corals and bivalves. New techniques, such as single foraminifera analyses within discreet layers of marine sediment (e.g. Rustic et al. 2015), provide important avenues to expand the temporal and spatial coverage of paleoENSO information. Terrestrial archives such as speleothems, tree rings, and lake sediments record past changes in precipitation. Combining these approaches requires intercalibration studies, which could expand the geographical coverage of ENSO reconstructions. These data, which are now integrated in a global database of past-interannual climate variability in the tropical oceans, facilitate intercomparisons of paleoclimate data and reconstructions with forced and unforced climate simulations. The combination of paleoclimate reconstructions and model simulations thus provides a framework to assess the mechanisms and forcing factors associated with past changes in tropical climate variability.

The achievements of this workshop were the identification of a list of key questions that urgently need to be addressed (see Box 1 and Fig. 1). Most recent studies still differ on the factors that control trends in ENSO during the Holocene: stochastic processes, solar insolation, response to the mean climate conditions, or a combination of these factors (Cobb et al. 2013; McGregor et al. 2013). Temporal trends in ENSO variance differ and are site specific, highlighting the importance of mapping geographical patterns as well

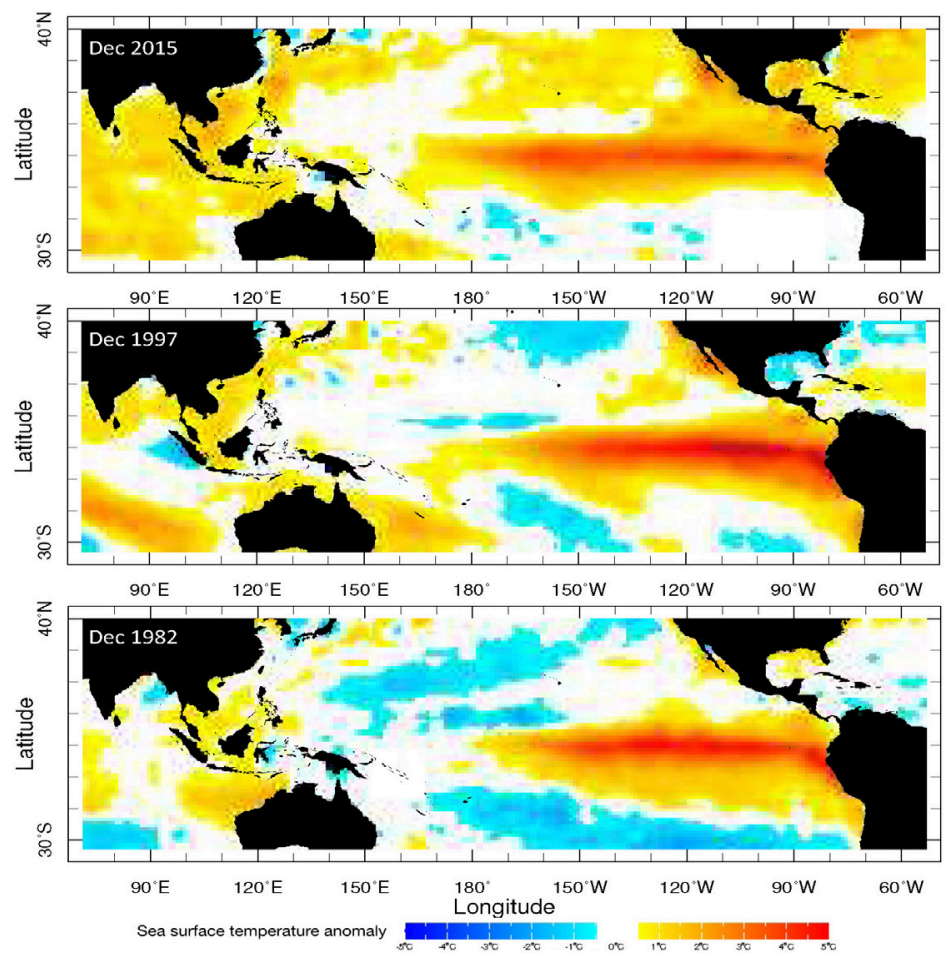

Figure 1: December sea surface temperature anomalies associated with 1982, 1997 and 2015 El Niño events. This figure shows the evolution of the spatial distribution of temperature anomalies across the Pacific Ocean over the past decades. Data from: iridl.Ideo.columbia.edu/SOURCES/.NOAA/.NCEP/.EMC/.CMB/.GLOBAL/. Reyn_SmithOlv2/ (Reynolds et al. 2002)

(1) How has ENSO changed over the geologic past? (2) Most likely causes of the observed changes?

(3) Is ENSO changing now in response to anthropogenic forcing of climate?

Box 1: Key questions discussed at the workshop.

as producing single-site records. Similarly, projected future changes in ENSO are model dependent (Collins et al. 2010). Advances in analytical precision and novel geochemical tools that have recently been developed provide a new impetus to address these research questions. We propose a road map to make progress on these research questions.

- Improve our understanding of the interactions between ENSO and other modes of variability, including the Indian Ocean Dipole and the East Asian Monsoon.

- Increase the temporal coverage to fully explore the response of ENSO to different mean background states (Last Glacial Maximum, Felis et al. 2012; previous interglacials; Pliocene).

- Reconstruct changes in the spatial patterns of ENSO (Fig. 1), which requires a denser coverage of proxy dataset (Freund et al. 2019).

- Build a global multi-archive database of interannual climate variability using a common metric. For this we need to homogenize methods for quantifying ENSO variance.

\section{AFFILIATIONS}

'Université de Nantes, Laboratoire de Planétologie et Géodynamique, France

${ }^{2}$ Research Center for Geotechnology, Indonesian Institute of Sciences (LIPI), Bandung, Indonesia ${ }^{3}$ Research School of Earth Sciences, Australian National University, Canberra, Australia

${ }^{4}$ ARC Centre of Excellence for Climate Extremes, Australian National University, Canberra, Australia ${ }^{5}$ MARUM - Center for Marine Environmental Sciences, University of Bremen, Germany

${ }^{6}$ School of Earth Atmosphere and Earth Sciences, Wollongong University, Australia

CONTACT

Mary Elliot: mary.elliot@univ-nantes.fr

REFERENCES

Cobb KM et al. (2013) Science: 339: 67-70

Collins M et al. (2010) Nat Geosci 3: 391-397

Emile-Geay J et al. (2020) In: McPhaden MJ et al. (Eds)

El Niño Southern Oscillation in a Changing

Climate. Wiley, ch. 5

Felis T et al. (2012) Nat Commun 3: 965

Freund MB et al. (2019) Nat Geosci 12: 450-455 McGregor HV et al. (2013) Nat Geosci 6: $969-953$ Reynolds RW et al. (2002) J Climate 15: 1609-1625 Rustic GT et al. (2015) Science 350: 1537-1541 